\title{
Disassociation of Histone Deacetylase-3 from Normal Huntingtin Underlies Mutant Huntingtin Neurotoxicity
}

\author{
Farah H. Bardai, Pragya Verma, Chad Smith, Varun Rawat, Lulu Wang, and Santosh R. D’Mello \\ Department of Molecular and Cell Biology, University of Texas at Dallas, Richardson, Texas 75080
}

Huntington's disease (HD) is caused by a polyglutamine expansion within the huntingtin (Htt) protein. Both loss of function of normal $\mathrm{Htt}$ and gain of a toxic function by the polyglutamine-expanded mutant $\mathrm{Htt}$ protein have been proposed to be responsible for HD, although the molecular mechanisms involved are unclear. We show that $\mathrm{Htt}$ is a neuroprotective protein in both HD-related and unrelated model systems. Neuroprotection by Htt is mediated by its sequestration of histone deacetylase-3 (HDAC3), a protein known to promote neuronal death. In contrast to the normal $\mathrm{Htt}$, mutant $\mathrm{Htt}$ interacts poorly with HDAC3. However, expression of mutant $\mathrm{Htt}$ liberates HDAC3 from $\mathrm{Htt}$, thus de-repressing its neurotoxic activity. Indeed, mutant $\mathrm{Htt}$ neurotoxicity is inhibited by the knockdown of HDAC3 and markedly reduced in HDAC3-deficient neurons. A reduction in Htt-HDAC3 interaction is also seen in neurons exposed to other apoptotic stimuli and in the striatum of R6/2 HD mice. Our results suggest that the robust interaction between Htt and HDAC3 along with the ability of mutant $\mathrm{Htt}$ to disrupt this association while not itself interacting with HDAC3 provides an explanation for both the loss-of-function and gain-of-toxic-function mechanisms proposed for HD. Moreover, our results identify HDAC3 as an essential player in mutant $\mathrm{Htt}$-induced neurodegeneration.

\section{Introduction}

Huntington's disease (HD) is an autosomal dominant neurodegenerative disease caused by a CAG trinucleotide repeat expansion within exon 1 of the huntingtin $(\mathrm{Htt})$ gene that produces a mutant protein with an elongated polyglutamine (polyQ) stretch near the $\mathrm{N}$ terminus (Zuccato et al., 2010; Crook and Housman, 2011; Ross and Tabrizi, 2011). The disease is characterized by selective and progressive degeneration of striatal GABAergic neurons and is manifested by adult-onset motor dysfunction, cognitive decline, and psychiatric disturbances. The polyQ expansion in mutant $\mathrm{Htt}$ (mut-Htt) is believed to confer a novel toxic gainof-function effect, although the pathogenic mechanisms involved are not well understood (Zuccato et al., 2010; Crook and Housman, 2011; Ross and Tabrizi, 2011). Several mechanisms have been proposed to be involved, including transcriptional dysregulation, excitotoxicity, impaired energy metabolism, abnormal protein cleavage and aggregation, defects in axonal transport, and abnormal protein-protein interactions (Zuccato et al., 2010; Crook and Housman, 2011; Ross and Tabrizi, 2011). Loss of normal Htt function has also been proposed to contribute to $\mathrm{HD}$. Indeed, heterozygous $\mathrm{Htt}$ knock-out mice as well as mice in which the $\mathrm{Htt}$ gene is selectively ablated in postmitotic neurons exhibit progressive neurodegeneration during adulthood (Nasir

\footnotetext{
Received Dec. 20, 2012; revised June 11, 2013; accepted June 12, 2013.

Author contributions: F.H.B., P.V., C.S., V.R., and S.R.D. designed research; F.H.B., P.V., C.S., V.R., L.W., and S.R.D. performed research; F.H.B. and S.R.D. analyzed data; S.R.D. wrote the paper.

This research was supported by National Institutes of Health Grant NS040408 (S.R.D.). We thank Jason Pfister and Sathi Mallick for performing confirmatory experiments. We are grateful to Troy Littleton and Dimitri Krainc for providing us with $\mathrm{Htt}$ and mutant-Htt plasmids.

Correspondence should be addressed to Santosh R. D'Mello, Department of Molecular and Cell Biology, University of Texas at Dallas, 800 West Campbell, Richardson, TX75080. E-mail: dmello@utdallas.edu.

DOI:10.1523/JNEUROSCI.5831-12.2013

Copyright $\odot 2013$ the authors $\quad 0270-6474 / 13 / 3311833-06 \$ 15.00 / 0$
}

et al., 1995; Dragatsis et al., 2000). Disease-associated loss of normal Htt has also been shown in mouse models of ischemia, trauma, and spinal cord injury (Zhang et al., 2003).

In this study, we examined the possibility that Htt has a broader role in maintaining neuronal survival, functioning by directly acting on proteins regulating neuronal death. We find that Htt not only protects against mut-Htt-induced toxicity but can also protect neurons in paradigms unrelated to HD. We present evidence showing that $\mathrm{Htt}$ acts by sequestration of histone deacetylase-3 (HDAC3), a protein with established neurotoxic activity (Bardai and D'Mello, 2011). Although interacting poorly with HDAC3 itself, we find that mut-Htt promotes the disassociation of HDAC3 from Htt. Mut-Htt neurotoxicity is greatly reduced in the absence of $\mathrm{HDAC} 3$, suggesting that $\mathrm{HDAC} 3$ is a key player in HD pathogenesis.

\section{Materials and Methods}

Materials. Flag-tagged HDAC3 expression plasmid was bought from Addgene. GFP- and RFP-tagged Htt plasmids were a kind gift from Dr. Troy Littleton (Massachusetts Institute of Technology, Cambridge, MA). The untagged Htt plasmids were a kind gift from Dr. Dimitri Krainc (Harvard Medical School, Boston, MA). All cell culture media and reagents were purchased from Invitrogen. Huntingtin antibody (catalog \#5656) was from Cell Signaling Technology. HDAC3 antibody (catalog \#H3034) used for immunoprecipitation was from Sigma-Aldrich and that for Western blot analysis was bought from Santa Cruz Biotechnology (catalog \#sc-11417). HDAC3 shRNA plasmids (TRCN0000039391 and TRCN0000039392), referred to here as HDAC3-shRNA1 and HDAC3shRNA2, respectively, and a control plasmid (pLKO.1) were purchased from Sigma-Aldrich. The ability of these shRNA constructs to suppress HDAC3 expression was shown previously (Bardai and D’Mello, 2011).

Culturing, treatment, and transfection of neurons. Cerebellar granule neurons (CGNs) were cultured from $7-8$ day old Wistar rats as described previously (D’Mello et al., 1993). All transfections were done on day 5 
using the calcium phosphate method as described previously (Bardai and D'Mello, 2011; Dastidar et al., 2011) and treated with either high potassium [HK; serum-free basal medium Eagle (BME) medium with $25 \mathrm{~mm} \mathrm{KCl}$ ] or low potassium (LK; serum-free BME medium) $8 \mathrm{~h}$ later unless the transfection was with shRNA plasmid, in which case treatment was done after $48 \mathrm{~h}$. Serum-free culture medium is particularly important for experiments with HDAC3 in CGNs because neurotoxicity is not observed in the presence of serum, presumably because of IGF-1 in serum. Viability of transfected neurons (identified by immunocytochemistry) was assessed $24 \mathrm{~h}$ after treatment by staining cell nuclei with 4',6'-diamidino-2-phenylindole hydrochloride (DAPI). When shRNA constructs were used, a GFP-expressing plasmid was cotransfected in a ratio of 1:6.5 to identify neurons expressing the shRNA. Cortical cultures were prepared from Wistar rats at embryonic day 16 or 17 as described previously (Majdzadeh et al., 2008). Cultures were kept in Neurobasal medium with $1 \%$ B27 supplement, $0.25 \%$ L-glutamine, $1 \%$ penicillin/streptomycin, $0.1 \%$ HEPES, and $1.1 \%$ sodium pyruvate without serum to minimize glial proliferation. Transfections were done on day 8 and treated with $1 \mathrm{~mm}$ homocysteic acid (HCA) 6 h later. Viability of transfected neurons was assessed after $14 \mathrm{~h}$.

Immunoprecipitation and Western blot. HEK293 cells were transfected with plasmids as indicated using Lipofectamine 2000. For cotransfection experiments, the amount of DNA was kept constant by using a "filler" plasmid, pLKO.1, in the control samples. For experiments using primary CGN cultures, the cells were treated with HK or LK media for $6 \mathrm{~h}$ on day 7. For R6/2 samples, mice were killed at 6 or 13 weeks, striatum, cortex, and cerebella were separated, and protein samples were prepared. For all endogenous samples, $1000 \mu \mathrm{g}$ of total protein was used for immunoprecipitation using $5 \mu \mathrm{g}$ of the appropriate antibody. Incubations for immunoprecipitation were done for $12-14 \mathrm{~h}$ with rocking at $4^{\circ} \mathrm{C}$. The immunoprecipitated proteins were subjected to SDS-PAGE and probed with the antibody as indicated.

shRNA-mediated knockdown. HDAC3 shRNA or control plasmids were cotransfected with GFP-tagged mut-Htt in 2:1 ratio for $48 \mathrm{~h}$. CGNs were then switched to HK media, whereas cortical cultures were left untreated. Viability of transfected neurons (GFP-positive) was assessed $24 \mathrm{~h}$ later.

Generation of $\mathrm{Hdac}^{-1-}$ conditional knock-out mice and cultures. Hdac $3^{-/-}$conditional knockout mice were generated as described previously (Bardai et al., 2012). Briefly, mice homozygous for loxP sites in the HDAC3 locus $\left(H d a c 3^{\text {neo-loxP }}\right)$ were bred to Nes-Cre transgenic mice (The Jackson Laboratory) that express the Cre recombinase throughout the developing CNS, allowing for the generation of CNS-specific $\mathrm{Hdac}^{+/-}$mice. These $\mathrm{Hdac} 3^{+/-}$mice were then interbred, and genotyping of pups was performed on the day of birth. Cortical neuron cultures were prepared from individual $\mathrm{Hdac}^{-/-}$and $\mathrm{Hdac}^{+/+}$pups on the day of birth (P0). The cultures were transfected with either GFP or mut-Htt plasmid on day 7 after plating, and viability was assessed $20 \mathrm{~h}$ later.

The R6/2 transgenic mouse model of HD. Female C57BL/6J (B6) mice hemizygous for the ovarian transplant of the truncated mutant $\mathrm{Htt}$ trans-
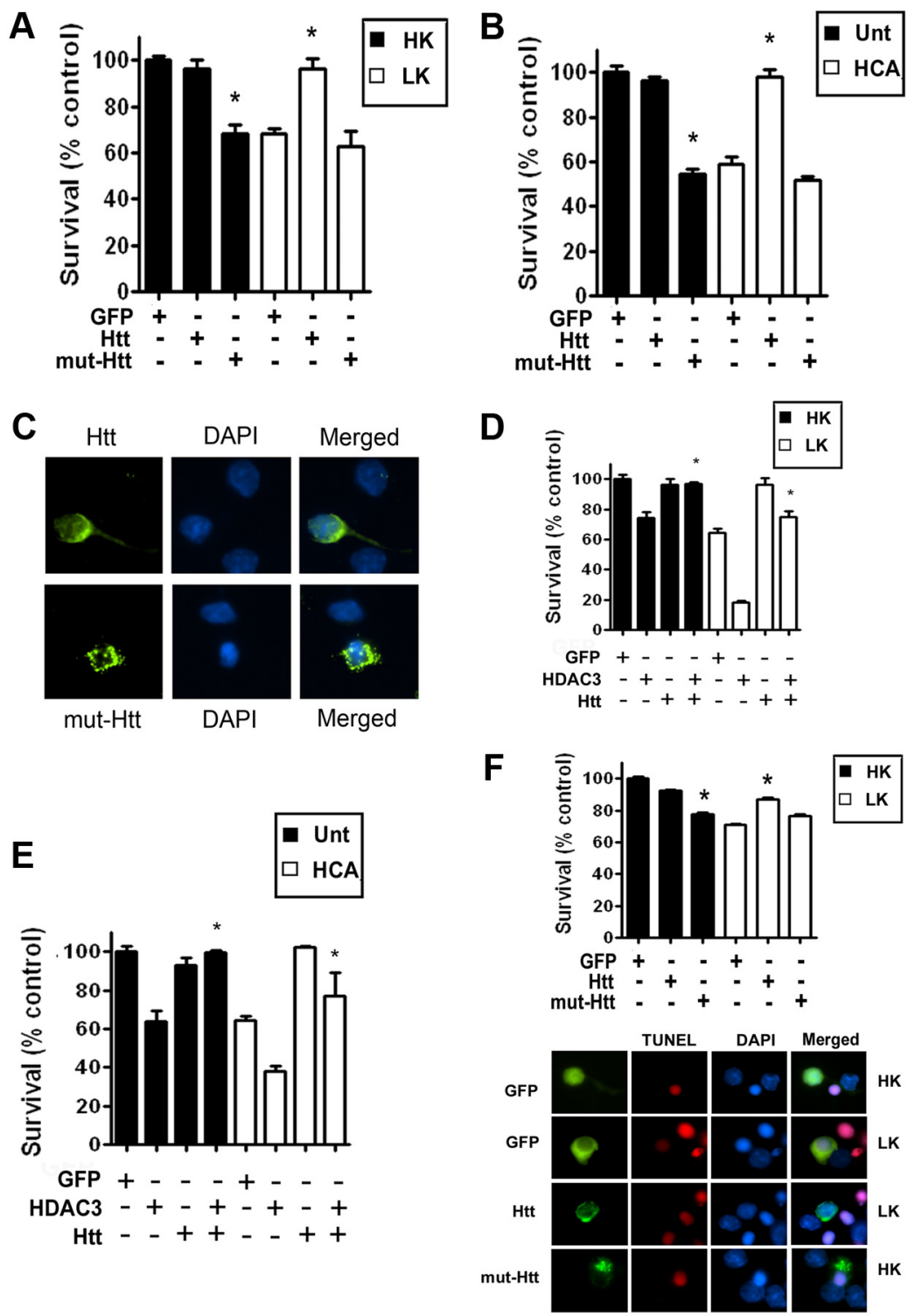

Figure 1. Htt is a neuroprotective protein. $\boldsymbol{A}$, Viability of CGNs transfected with GFP, $\mathrm{Htt}_{\mathrm{Q} 15}-\mathrm{GFP}$ (Htt), or Htt ${ }_{\mathrm{Q} 138}-\mathrm{GFP}$ (mut$\mathrm{Htt}$ ) and treated with HK or LK medium. $\boldsymbol{B}$, Viability of cortical neurons transfected with GFP, Htt, or mut-Htt and either untreated (Unt) or treated with HCA. A similar level of toxicity by $\mathrm{Htt}_{0138}$ and protection by $\mathrm{Htt}_{015}$ was observed when RFP-tagged forms of these plasmids as well as untagged plasmids expressing $\mathrm{N}$-terminal 480 aa of $\mathrm{Htt}$ with 68 and $17 \mathrm{glutamine}$ repeats, respectively, were used (data not shown). C, Immunofluorescence images showing overexpressed Htt or mut-Htt proteins in CGNs treated with HK. D, Viability of CGNs transfected with GFP, Htt, and HDAC3 in the combinations shown and then treated with HK or LK medium. $\boldsymbol{E}$, Viability of cortical neurons transfected with GFP, Htt, and HDAC3 in the combinations shown and either untreated (Unt) or treated with HCA. $\boldsymbol{F}$, Immunofluorescent image of CGNs transfected with GFP, $\mathrm{Htt}_{\mathrm{Q} 15}-\mathrm{GFP}(\mathrm{Htt})$, or $\mathrm{Htt}_{\mathrm{Q} 138}-\mathrm{GFP}$ (mut-Htt) and treated with HK or LK medium. Dead cells identified by TUNEL overlap almost completely with DAPI staining. Quantification of TUNEL data obtained from three separate experiments. For all the graphs, data represented are mean \pm SD from three separate experiments done in duplicate. ${ }^{*} p<0.05$ by one-way ANOVA with Bonferroni's multiple comparison test.

gene containing $160 \pm$ glutamines in the polyQ region were bred with wild-type CBA/J (CBA) male mice. Both mice were purchased from The Jackson Laboratory. Only F1 pups were used in the experiments. Genotyping of pups was performed using the primers recommended by The Jackson Laboratory. At 6 and 13 weeks after birth, mice with the transgene (R6/2) or their wild-type littermates of the same gender were killed, the brains were dissected, and the striatum, cortex, and cerebellum were separated. Lysates were made from the brain tissue and used for immunoprecipitation assays.

TUNEL staining. TUNEL assays were performed using the fluorometric in situ cell death detection kit, TMR red from Roche Applied Science, 


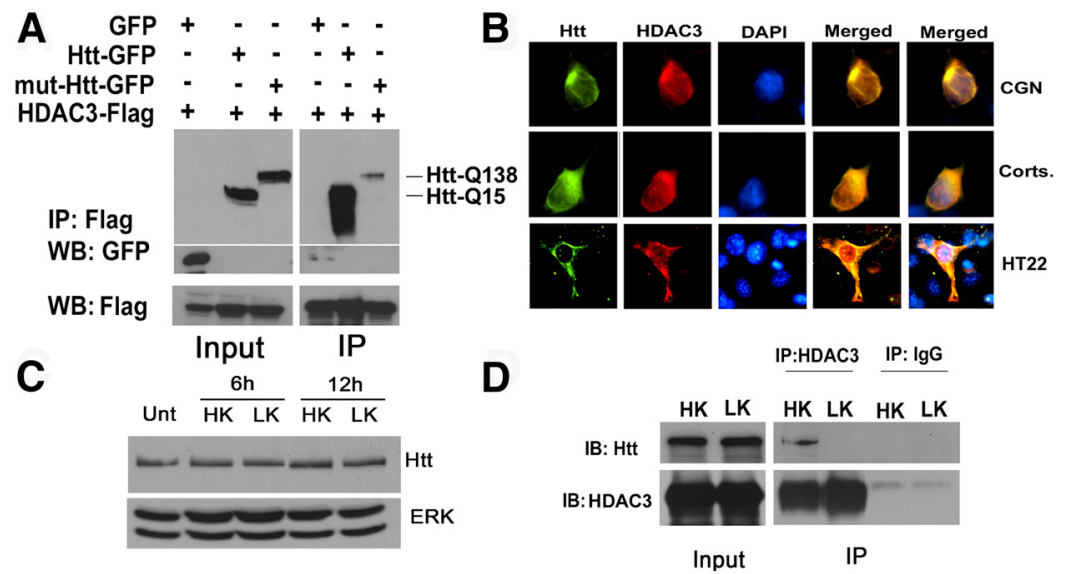

$\mathbf{E}$
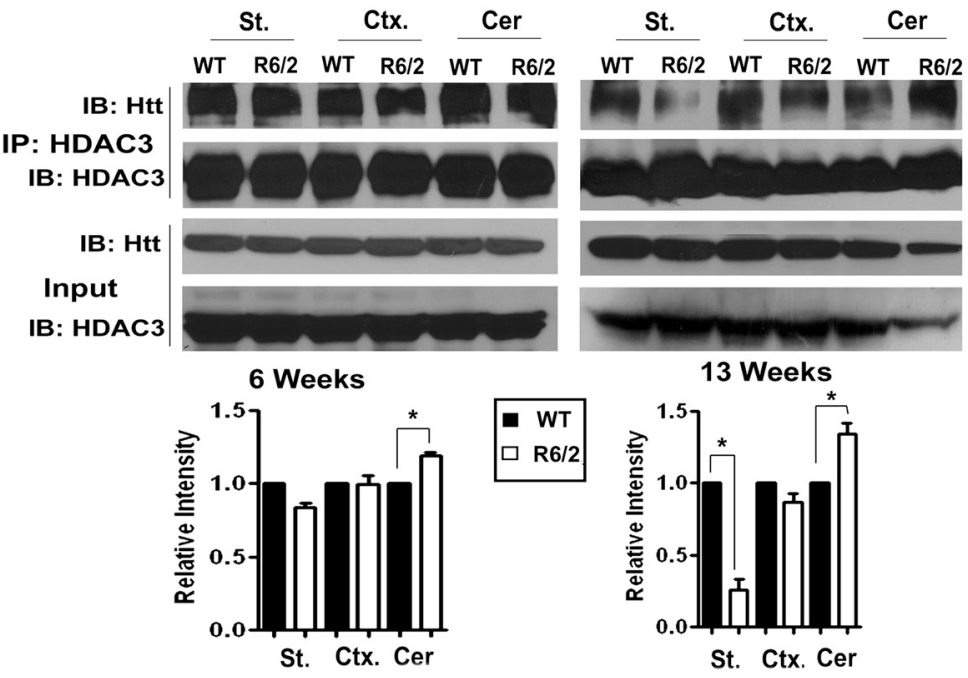

Figure 2. Neuroprotection by Htt involves interaction with and sequestration of HDAC3. A, Lysates from HEK293 cells cotransfected with HDAC3-Flag and GFP, Htt-GFP, or mut-Htt-GFP were immunoprecipitated with a Flag antibody, and the interaction was evaluated after Western blotting with a GFP antibody. Preimmunopreciptation lysate was also run to show expression levels. The same membranes were reprobed with Flag antibody to show HDAC3 expression and pull down. Unt, Untreated. $\boldsymbol{B}$, Immunofluorescence pictures showing colocalization of Htt and HDAC3 in CGNs, cortical neurons, and HT22 cells. C, CGNs were treated with HK or LK medium for 6 or $12 \mathrm{~h}$, and the lysates were subjected to Western blotting and probed for $\mathrm{Htt}$. The same membrane was reprobed with ERK to show equal loading. $\boldsymbol{D}$, Lysates from HKor LKmedium-treated CGNs were immunoprecipitated with antibodies against HDAC3 or lgG, and the immunoprecipitates were subjected to Western blotting with an Htt and HDAC3 antibody. Preimmunoprecipitation lysates show equal expression levels. $\boldsymbol{E}_{\text {, }}$ Lysates from the striatum (St), cortex (Ctx), and cerebellum (Cer) of 6- and 13-week-old R6/2 mice and wild-type littermates were immunoprecipitated with HDAC3 antibody, and the interaction was evaluated after Western blotting with an Htt antibody, followed by reprobing of the blot with HDAC3 antibody. The bottom two panels show preimmunoprecipitation lysates subjected to Western blotting and probed with $\mathrm{Htt}$ and HDAC3 antibodies. The graphs show quantification of immunoprecipitation data from three separate experiments. For each condition, the $R 6 / 2$ intensity is normalized to the wild-type intensity for that brain part for that age. ${ }^{*} p<0.05$ by one-way ANOVA with Bonferroni's multiple comparison test. survival-promoting effect of neuronal activity in vivo. Treatment with nondepolarizing medium (LK) results in cell death of these neurons (D'Mello et al., 1993). Expression of $\mathrm{Htt}_{588-\mathrm{Q} 15}$ (henceforth referred to as $\mathrm{Htt}$ ), composed of the $\mathrm{N}$-terminal 588 aa of $\mathrm{Htt}$ and containing 15 glutamine repeats, completely protects against LK-induced death (Fig. $1 A, C$ ). In contrast, expression of a polyQ-expanded form of the protein, $\mathrm{Htt}_{588-\mathrm{Q} 138}$ (henceforth referred to as mut-Htt) promoted death of otherwise healthy neurons. A similar protection by Htt was observed in cortical neurons induced to die by treatment with HCA (Fig. 1B). These results demonstrate that elevated Htt expression protects neurons even in experimental models not directly related to HD pathogenesis. Results obtained using DAPI staining of the nuclei were confirmed using the TUNEL assay (Fig. $1 F$ ).

\section{Htt interacts with HDAC3, and this interaction is reduced in apoptotic conditions}

LK-induced death of CGNs as well as apoptosis in cortical neurons and HT22 cells is dependent on HDAC3 (Bardai and D’Mello, 2011). We tested the possibility that neuroprotection by Htt is mediated by suppressing the neurotoxic activity of HDAC3. As shown in Figure 1, D and $E$, HDAC3-induced neurotoxicity in both CGNs and cortical neurons is substantially reduced when $\mathrm{Htt}$ is coexpressed. To examine how Htt inhibits HDAC3 neurotoxicity, we investigated whether the two proteins interact. Coimmunoprecipitation analysis revealed robust interaction between HDAC3 and $\mathrm{Htt}$ (Fig. 2A). In comparison, interaction with mut-Htt was weak. HDAC3 and $\mathrm{Htt}$ colocalize in the cytoplasm of CGNs, cortical neurons, and HT22 cells when the two proteins are expressed, confirming interaction (Fig. 2B). Additionally, interaction between endogenous $\mathrm{Htt}$ and HDAC3 is observed in CGNs.

Interestingly, although $\mathrm{Htt}$ and HDAC3 levels are similar in healthy and according to the instructions of the manufacturer. Briefly, transfected neurons were fixed in $4 \%$ paraformaldehyde. After washing with PBS, the neurons were permeabilized with $0.1 \%$ Triton X-100 in $0.1 \%$ sodium citrate solution at $4^{\circ} \mathrm{C}$ and incubated with fluorescein-conjugated TUNEL reaction mixture at $37^{\circ} \mathrm{C}$ for $1 \mathrm{~h}$ in the dark. After reaction termination, the cells were washed with PBS and stained with DAPI before visualization under a fluorescent microscope.

\section{Results}

Ectopic expression of $\mathrm{Htt}$ protects neurons from apoptosis To examine whether Htt has neuroprotective functions, we expressed it in cultured CGNs, a neuronal type from a brain region not affected in HD. CGNs can be maintained in medium containing depolarizing levels of potassium (HK), which mimics the dying neurons, interaction between them can only be detected in healthy neurons (Fig. 2C,D; Bardai and D'Mello, 2011). Reduction in HDAC3-Htt interaction was also observed under conditions of neurodegeneration in the R6/2 transgenic mouse model of $\mathrm{HD}$, which express an N-terminal fragment of mut-Htt. As seen in Figure 2E, whereas interaction was similar in the striatum of presymptomatic R6/2 mice (6 weeks old), it was markedly reduced at 13 weeks when neuropathology and behavioral deficits are obvious. A discernible reduction was observed in the R6/2 cortex, which is also affected in HD but not in the cerebellum. In fact, Htt-HDAC3 interaction is elevated in the cerebellum, possibly explaining its relative resistance to degeneration in HD. Together, these results suggest that Htt protects neurons by se- 
questering HDAC3 through physical interaction and that the liberation of HDAC3 from Htt de-represses its neurotoxic activity leading to cell death.

\section{Mut-Htt neurotoxicity is dependent on HDAC3}

HDAC3 neurotoxicity is inhibited by treatment with IGF-1 or the expression of Akt, a kinase activated by IGF-1 treatment (Bardai and D'Mello, 2011). We showed previously that protection by IGF-1/Akt against HDAC3 neurotoxicity is mediated by the inhibition of glycogen synthase kinase-3 $\beta$ (GSK3 $\beta)$, a kinase that is widely implicated in promoting neuronal death and that phosphorylates HDAC3 (Bardai and D'Mello, 2011). Coincidentally, toxicity by mut-Htt is also inhibited by IGF-1 and Akt (Humbert et al., 2002; Rangone et al., 2005). Additionally, and as demonstrated previously using chemical inhibitors (Carmichael et al., 2002; Valencia et al., 2012), suppression of GSK3 $\beta$ protects against mut-Htt toxicity (Fig. $3 A$ ). These results suggest that mut-Htt requires HDAC3 for its neurotoxic effect. Consistent with this conclusion, shRNA-mediated knockdown of HDAC3 reduces mut-Htt toxicity in both CGNs and cortical neurons (Fig. $3 B, C)$. Additionally, HDAC3-deficient neurons display reduced vulnerability to mut-Htt toxicity (Fig. 3D). Because mut$\mathrm{Htt}$ promotes death and given that HDAC3 is necessary for its neurotoxic effect, it could be predicted that mut-Htt disrupts the association between $\mathrm{Htt}$ and HDAC3. This is what is observed when mut-Htt is coexpressed with $\mathrm{Htt}$ and HDAC3 in HEK293 cells (Fig. $3 F$ ). Conversely, the overexpression of $\mathrm{Htt}$ reduces mut-Htt toxicity when coexpressed in CGNs (Fig. 3G). Although the protection by $\mathrm{Htt}$ in neurons appears to contradict the disruption of Htt-HDAC3 interaction by mut-Htt observed in HEK293 cells, it is possible that liberation of HDAC3 depends also on additional factors that are present in HEK293 cells but not in neurons. While additional studies to identify such factors are necessary, one candidate is GSK3 $\beta$ activity, which is normally low in healthy neurons but the elevation of which causes neurodegeneration.

\section{Discussion}

Our report is significant for several reasons. First, we show that normal Htt is a neuroprotective protein. Other studies have reached a similar conclusion. However, in general, these studies have used neurons cultured from Htt-expressing transgenic mice or cell lines stably expressing Htt (Rigamonti et al., 2000; Leavitt et al., 2001, 2006; Van Raamsdonk et al., 2005). Given that Htt has diverse functional actions, the protection seen in these cells could conceivably be attributable to
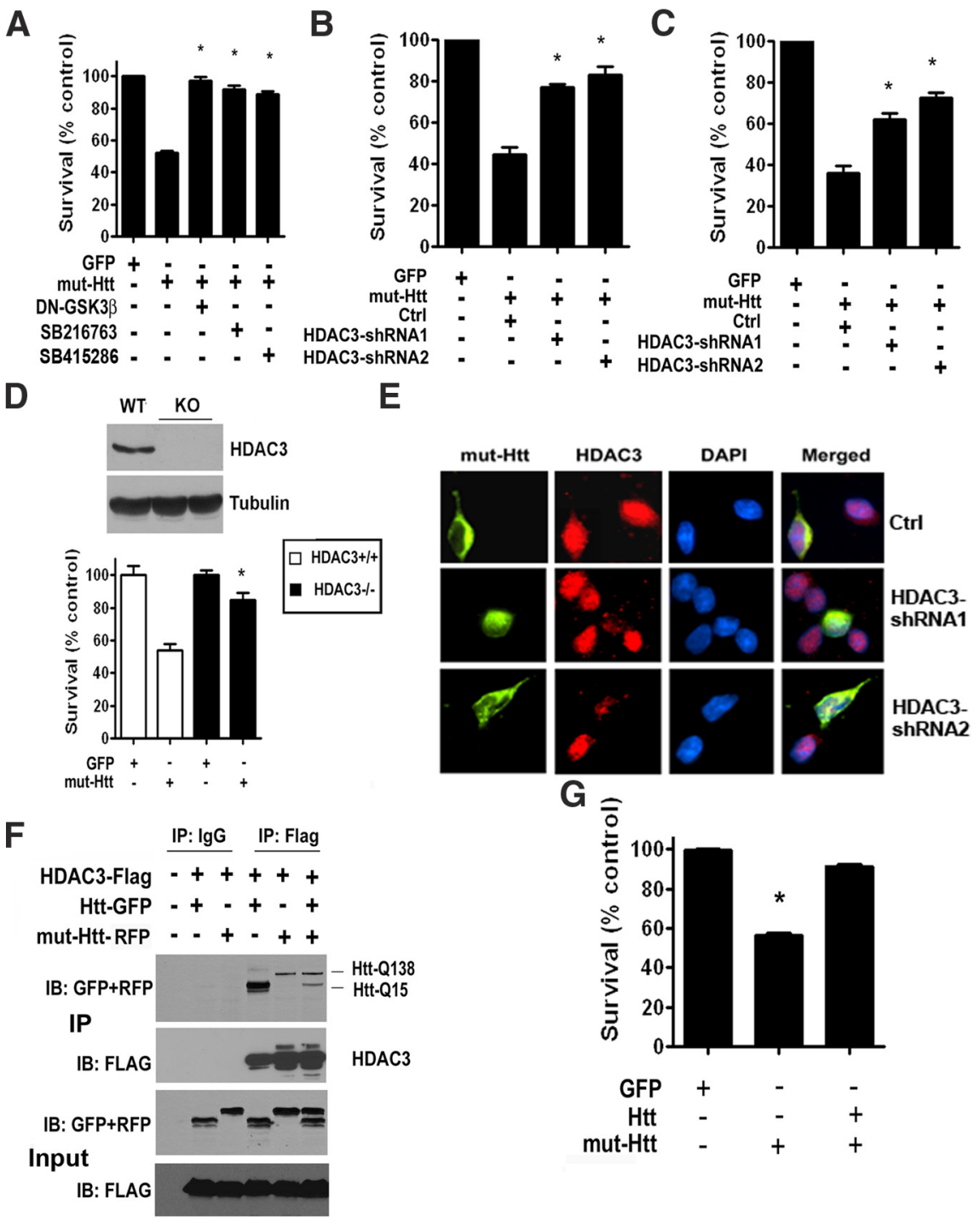

G

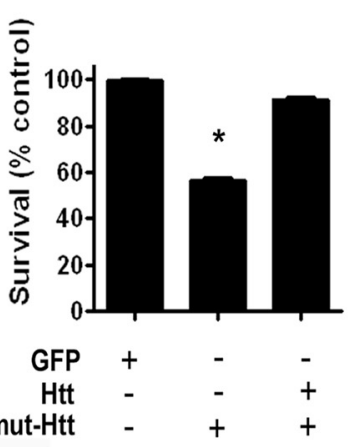

Figure 3. Mut-Htt neurotoxicity is dependent on HDAC3. A, Viability of CGNs transfected with GFP, mut-Htt, or mut-Htt cotransfected with dominant-negative GSK3 $\beta$ (DN-GSK3 $\beta$ ) or mut-Htt treated with two separate GSK3 $\beta$ inhibitors, SB216763 and SB415286. $\boldsymbol{B}, \boldsymbol{C}$, Viability of CGNs $(\boldsymbol{B})$ or cortical neurons $(\boldsymbol{C})$ transfected with GFP or mut-Htt and either of two HDAC3 shRNA constructs (HDAC3-shRNA1 and HDAC3-shRNA2) or a control (Ctrl) construct (pLK0.1). D, Viability of cortical neurons cultured from Nestin-Cre-Hdac $3^{f / / f l}$ mice $\left(H D A C 3^{-/-}\right)$or control Nestin-Cre-Hdac $3^{+/+}$littermates $\left(H D A C 3^{+/+}\right)$transfected with GFP or mut-Htt. K0, Knock-out; WT, wild type. $\boldsymbol{E}$, Immunofluorescence pictures of CGNs cotransfected with mut-Htt with one of the two HDAC3 shRNAs costained with GFP and endogenous HDAC3 antibody showing the expression of mut-Htt and knockdown of HDAC3. F, Lysates from HEK293 cells cotransfected with HDAC3-Flag and Htt, mut-Htt, or both were immunoprecipitated with Flag or lgG antibody, and the interaction was evaluated after Western blotting with GFP and RFP antibodies. The same membrane was reprobed with HDAC3 to show equal pull down. Preimmunoprecipitation lysates (Input) show similar expression levels of Htt proteins and HDAC3. IB, Immunoblot; IP, immunoprecipitation. G, Viability of CGNs transfected with GFP, mut-Htt, or mut-Htt plus Htt. For all the graphs, data represented are mean \pm SD from three separate experiments done in duplicate. ${ }^{*} p<0.05$ by one-way ANOVA with Bonferroni's multiple comparison test.

secondary effects resulting from long-term Htt expression. Similarly, the degeneration seen in mice lacking Htt could be the consequence of developmental defects, general biochemical abnormalities such as reduced energy metabolism, or defects in processes such as axonal transport. We show that acute expression of Htt protects primary neurons against death by mut-Htt toxicity as well as in paradigms unconnected to $\mathrm{HD}$, demonstrating that it has direct and broad neuroprotective activity. This supports the results of Ho et al. (2001) who showed that Htt protected against mut-Htt when the two proteins were coexpressed in cell lines. In a separate study, Zhang et al. (2003) found that siRNA-mediated knockdown of en- 

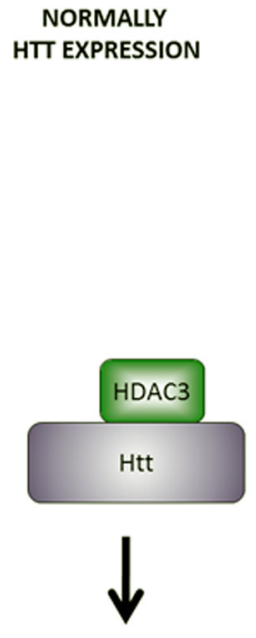

SURVIVAL
IN HD

MUTANT HTT EXPRESSION

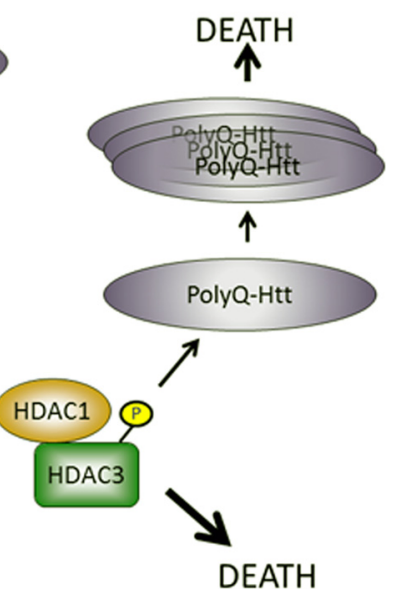

Figure 4. Model to explain protection against mut-Htt toxicity by IGF-1, Akt, GSK3 $\beta$ inhibition, HDAC3 inhibition, and wildtype Htt. Normally or when wild-type Htt is overexpressed, Htt sequesters HDAC3 inhibiting its neurotoxic activity. In HD (when normal $\mathrm{Htt}$ is reduced) or when mut-Htt is overexpressed, $\mathrm{HDAC} 3$ is liberated from $\mathrm{Htt}$, possibly as a result of its phosphorylation by GSK3 $\beta$. GSK3 $\beta$ phosphorylation may also activate the neurotoxic activity of HDAC3 independent of its effect on Htt-HDAC3 interaction. Neuronal death caused by HDAC3 can be inhibited by IGF-1, Akt expression, or with GSK $\beta$ inhibitors (GSK $\beta \mathrm{i}$ ), which all block HDAC3 phosphorylation, by the overexpression of $\mathrm{Htt}$, which resequesters HDAC3, or by HDAC inhibitors, which inhibit HDAC catalytic activity. Although mut-Htt triggers HDAC3 disassociation from Htt in HD, in other contexts, different apoptotic stimuli (like LK in (GNs) could promote HDAC3 disassociation. In addition to promoting neuronal death directly, HDAC3 could promote mut-Htt deacetylation, a modification that has been reported to induce accumulation of soluble toxic mut-Htt oligomers (Jeong et al., 2009). Mut-Htt deacetylation has been ascribed to HDAC1. We previously described that HDAC3 neurotoxicity is dependent on its interaction with HDAC1 (Bardai et al., 2012), suggesting that mut-Htt deacetylation is mediated by an HDAC1-HDAC3 complex. Neuroprotection by HDAC inhibitors could be mediated through the inhibition of HDAC1-HDAC3 activity. Potent protection in HD mouse models by inhibitors targeting both HDAC3 and HDAC1 has been reported recently (Jia et al., 2012).

dogenous $\mathrm{Htt}$ induced death in a neuronal cell line but not in nonneuronal cells.

Second, we show for the first time that Htt interacts with HDAC3, a protein that is selectively toxic to neurons (Bardai and D’Mello, 2011). Our results suggest that Htt protects neurons through the sequestration of HDAC3. It deserves mention that a recent publication reported that $\mathrm{R} 6 / 2 \mathrm{HD}$ mice deficient in HDAC3 do not display reduction in disease severity or progression (Moumné et al., 2012). However, that study had used $\mathrm{Hdac}^{+/-}$heterozygotes in which expression of HDAC3 was reduced by only $20 \%$, with no reduction observed in cytoplasmic HDAC3 (Moumné et al., 2012). Moreover, compensatory effects by other HDAC proteins cannot be excluded in this total knockout line. In our experiments, expression of HDAC3 was virtually undetectable using both shRNA and neurons from $\mathrm{Hdac}^{-/-}$ conditional knock-out mice.

Third, our results provide a possible explanation for both the loss-of-function and gain-of-function mechanisms proposed for $\mathrm{HD}$ pathogenesis. Loss of Htt function would de-repress the neurotoxic activity of HDAC3. HD neuropathology is also observed in mouse models in which mut-Htt is expressed in the context of normal levels of Htt. This gain-of-function effect can be explained by the ability of mut-Htt to promote disassociation of HDAC3 from Htt. Exactly how this is achieved remains to be clarified. It is possible that mut-Htt activates GSK3 $\beta$, reducing its affinity for Htt. Phosphorylation of HDAC3 by GSK3 $\beta$ is necessary for its neurotoxicity (Bardai and D'Mello, 2011). Consistent with the idea that liberation of HDAC3 from $\mathrm{Htt}$ is a key event in neurotoxicity by mut-Htt is the finding that the level of interaction is reduced in the striatum of symptomatic R6/2 mice but not in presymptomatic mice. Htt-HDAC3 interaction was not reduced in the cerebellum. Because mut-Htt is expressed in both brain regions, it is not clear why the interaction with $\mathrm{Htt}$ is not disrupted in the cerebellum. This suggests that, although necessary, the presence of mut$\mathrm{Htt}$ is not sufficient for the disassociation of HDAC3 from Htt and that other factors are also involved. These may include extrinsic factors, such as IGF-1, which is highly produced in the cerebellum and through which activation of Akt can inhibit GSK3 $\beta$.

Most importantly, our results provide a unifying model (Fig. 4) that explains how a seemingly disparate group of pharmacological agents and molecules, namely normal Htt (Rigamonti et al., 2000; Leavitt et al., 2001, 2006), IGF1(Humbert et al., 2002; Rangone et al., 2005), pan-HDAC and HDAC3-selective inhibitors (Thomas et al., 2008; Aiken et al., 2009; Jia et al., 2012), HDAC3 knockdown (in Caenorhabditis elegans) (Bates et al., 2006), and GSK3 $\beta$ inhibitors (Carmichael et al., 2002; Valencia et al., 2012), all protect against mut-Htt-induced neurodegeneration. Once HDAC3 dissociates from $\mathrm{Htt}$, it is possible that the resulting neurotoxicity is attributable to transcriptional alterations involving genes regulated by HDAC3. Indeed, transcriptional dysregulation has been implicated in the pathogenesis of HD (Cha, 2000; Steffan et al., 2001). We could speculate that one such downstream target of HDAC3-mediated repression could be BDNF, a neurotrophic factor necessary for the survival of striatal and cortical neurons. This would be consistent with the finding that $\mathrm{Htt}$ promotes the expression of BDNF in cortical neurons (by inhibiting HDAC3-mediated repression of its transcription) and that this activity is lost in the mutant form of the protein (Zuccato et al., 2001).

\section{References}

Aiken CT, Steffan JS, Guerrero CM, Khashwji H, Lukacsovich T, Simmons D, Purcell JM, Menhaji K, Zhu YZ, Green K, Laferla F, Huang L, Thompson LM, Marsh JL (2009) Phosphorylation of threonine 3: implications for Huntingtin aggregation and neurotoxicity. J Biol Chem 284:2942729436. CrossRef Medline

Bardai FH, D'Mello SR (2011) Selective toxicity by HDAC3 in neurons: regulation by Akt and GSK3 $\beta$. J Neurosci 31:1746-1751. CrossRef Medline

Bardai FH, Price V, Zaayman M, Wang L, D'Mello SR (2012) Histone deacetylase-1 (HDAC1) is a molecular switch between neuronal survival and death. J Biol Chem 287:35444-35453. CrossRef Medline

Bates EA, Victor M, Jones AK, Shi Y, Hart AC (2006) Differential contributions of Caenorhabditis elegans histone deacetylases to huntingtin polyglutamine toxicity. J Neurosci 26:2830-2838. CrossRef Medline

Carmichael J, Sugars KL, Bao YP, Rubinsztein DC (2002) Glycogen synthase kinase-3beta inhibitors prevent cellular polyglutamine toxicity caused by the Huntington's disease mutation. J Biol Chem 277:33791-33798. CrossRef Medline

Cha JH (2000) Transcriptional dysregulation in huntington's disease. Trends Neurosci 23:387-392. CrossRef Medline

Crook ZR, Housman D (2011) Huntington's disease: can mice lead the way 
to treatment? Neuron [Erratum (2011) 69:1038] 69:423-435. CrossRef Medline

Dastidar SG, Landrieu PM, D’Mello SR (2011) FoxG1 promotes the survival of postmitotic neurons. J Neurosci 31:402-413. CrossRef Medline

D’Mello SR, Galli C, Ciotti T, Calissano P (1993) Induction of apoptosis in cerebellar granule neurons by low potassium: inhibition of death by insulin-like growth factor I and cAMP. Proc Natl Acad Sci U S A 90: 10989-10993. CrossRef Medline

Dragatsis I, Levine MS, Zeitlin S (2000) Inactivation of Hdh in the brain and testis results in progressive neurodegeneration and sterility in mice. Nat Genet 26:300-306. CrossRef Medline

Ho LW, Brown R, Maxwell M, Wyttenbach A, Rubinsztein DC (2001) Wild type huntingtin reduces the cellular toxicity of mutant huntingtin in mammalian cell models of huntington's disease. J Med Genet 38:450452. CrossRef Medline

Humbert S, Bryson EA, Cordelières FP, Connors NC, Datta SR, Finkbeiner S, Greenberg ME, Saudou F (2002) The IGF-1/akt pathway is neuroprotective in Huntington's disease and involves Huntingtin phosphorylation by akt. Dev Cell 2:831-837. CrossRef Medline

Jeong H, Then F, Melia TJ Jr, Mazzulli JR, Cui L, Savas JN, Voisine C, Paganetti P, Tanese N, Hart AC, Yamamoto A, Krainc D (2009) Acetylation targets mutant huntingtin to autophagosomes for degradation. Cell 137: 60-72. CrossRef Medline

Jia H, Pallos J, Jacques V, Lau A, Tang B, Cooper A, Syed A, Purcell J, Chen Y, Sharma S, Sangrey GR, Darnell SB, Plasterer H, Sadri-Vakili G, Gottesfeld JM, Thompson LM, Rusche JR, Marsh JL, Thomas EA (2012) Histone deacetylase (HDAC) inhibitors targeting HDAC3 and HDAC1 ameliorate polyglutamine-elicited phenotypes in model systems of huntington's disease. Neurobiol Dis 46:351-361. CrossRef Medline

Leavitt BR, Guttman JA, Hodgson JG, Kimel GH, Singaraja R, Vogl AW, Hayden MR (2001) Wild-type huntingtin reduces the cellular toxicity of mutant huntingtin in vivo. Am J Hum Genet 68:313-324. CrossRef Medline

Leavitt BR, van Raamsdonk JM, Shehadeh J, Fernandes H, Murphy Z, Graham RK, Wellington CL, Raymond LA, Hayden MR (2006) Wild-type huntingtin protects neurons from excitotoxicity. J Neurochem 96:1121-1129. CrossRef Medline

Majdzadeh N, Wang L, Morrison BE, Bassel-Duby R, Olson EN, D’Mello SR (2008) HDAC4 inhibits cell-cycle progression and protects neurons from cell death. Dev Neurobiol 68:1076-1092. CrossRef Medline

Moumné L, Campbell K, Howland D, Ouyang Y, Bates GP (2012) Genetic knock-down of HDAC3 does not modify disease-related phenotypes in a mouse model of huntington's disease. PLoS One 7:e31080. CrossRef Medline
Nasir J, Floresco SB, O’Kusky JR, Diewert VM, Richman JM, Zeisler J, Borowski A, Marth JD, Phillips AG, Hayden MR (1995) Targeted disruption of the huntington's disease gene results in embryonic lethality and behavioral and morphological changes in heterozygotes. Cell 81:811-823. CrossRef Medline

Rangone H, Pardo R, Colin E, Girault JA, Saudou F, Humbert S (2005) Phosphorylation of arfaptin 2 at Ser260 by akt inhibits PolyQ-huntingtininduced toxicity by rescuing proteasome impairment. J Biol Chem 280: 22021-22028. CrossRef Medline

Rigamonti D, Bauer JH, De-Fraja C, Conti L, Sipione S, Sciorati C, Clementi E, Hackam A, Hayden MR, Li Y, Cooper JK, Ross CA, Govoni S, Vincenz C, Cattaneo E (2000) Wild-type huntingtin protects from apoptosis upstream of caspase-3. J Neurosci 20:3705-3713. Medline

Ross CA, Tabrizi SJ (2011) Huntington's disease: From molecular pathogenesis to clinical treatment. Lancet Neurol 10:83-98. CrossRef Medline

Steffan JS, Bodai L, Pallos J, Poelman M, McCampbell A, Apostol BL, Kazantsev A, Schmidt E, Zhu YZ, Greenwald M, Kurokawa R, Housman DE, Jackson GR, Marsh JL, Thompson LM (2001) Histone deacetylase inhibitors arrest polyglutamine-dependent neurodegeneration in Drosophila. Nature 413:739-743. CrossRef Medline

Thomas EA, Coppola G, Desplats PA, Tang B, Soragni E, Burnett R, Gao F, Fitzgerald KM, Borok JF, Herman D, Geschwind DH, Gottesfeld JM (2008) The HDAC inhibitor $4 \mathrm{~b}$ ameliorates the disease phenotype and transcriptional abnormalities in huntington's disease transgenic mice. Proc Natl Acad Sci U S A 105:15564-15569. CrossRef Medline

Valencia A, Sapp E, Reeves PB, Alexander J, Masso N, Li X, Kegel KB, DiFiglia M (2012) Reagents that block neuronal death from huntington's disease also curb oxidative stress. Neuroreport 23:10-15. CrossRef Medline

Van Raamsdonk JM, Pearson J, Rogers DA, Bissada N, Vogl AW, Hayden MR, Leavitt BR (2005) Loss of wild-type huntingtin influences motor dysfunction and survival in the YAC128 mouse model of huntington disease. Hum Mol Genet 14:1379-1392. CrossRef Medline

Zhang Y, Li M, Drozda M, Chen M, Ren S, Mejia Sanchez RO, Leavitt BR, Cattaneo E, Ferrante RJ, Hayden MR, Friedlander RM (2003) Depletion of wild-type huntingtin in mouse models of neurologic diseases. J Neurochem 87:101-106. CrossRef Medline

Zuccato C, Ciammola A, Rigamonti D, Leavitt BR, Goffredo D, Conti L, MacDonald ME, Friedlander RM, Silani V, Hayden MR, Timmusk T, Sipione S, Cattaneo E (2001) Loss of huntingtin-mediated BDNF gene transcription in huntington's disease. Science 293:493-498. CrossRef Medline

Zuccato C, Valenza M, Cattaneo E (2010) Molecular mechanisms and potential therapeutical targets in huntington's disease. Physiol Rev 90:905981. CrossRef Medline 